\title{
Identification of meteoric diagenetic transformation of fine-grained carbonates using clumped isotopes
}

\author{
AvNI PATEL ${ }^{1}$, CÉDRIC M. JOHN ${ }^{2}$, Claire VEILlARD ${ }^{3}$
}

1avni1@ualberta.ca

${ }^{2}$ cedric.john@imperial.ac.uk

33claire.veillard14@imperial.ac.uk

Accurate identification of diagenetic events is critical for understanding and predicting porosity changes occurring in carbonate systems. Using a novel, analytical approach comprising clumped isotope thermometry, stable isotope analysis and petrographic techniques, we differentiate shallow burial diagenesis from a later meteoric stage in two stratigraphically equivalent sections located $60 \mathrm{~km}$ apart in the HaushiHuqf, Oman. In thin section, differences in crystal morphology and luminosity patterns suggest at least two distinct diagenetic environments. Clumped isotope thermometry defines two diagenetic endmembers: $\Delta 47_{\text {(burial) }}=0.63 \pm 0.005 \%$ and $\Delta 47_{\text {(meteoric) }}=0.703 \pm$ $0.004 \%$, which correspond to equilibration temperatures of $47 \pm 1^{\circ} \mathrm{C}$ and $21 \pm 1^{\circ} \mathrm{C}$, respectively. Stable isotope values define a meteoric mixing line, suggesting increasing interaction between the carbonates and Pleistocene meteoric fluids up sectionin the vadose-zone. Variable fractions of mixing between the two clumped isotope endmembers account for the range of clumped values and confirms this model. The study presents the first application of clumped isotopes in fine-grained Cretaceous carbonates for meteoric diagenesis, and highlights the utility of these techniques to constrain the paragenesis of diagenetic events in shallowly buried platforms. 